\title{
Clinical and Laboratory Profile of HIV-Positive Patients at the Moment of Diagnosis in Bahia, Brazil
}

\author{
Márcia Sampaio Sá ${ }^{1,2}$, Julio Sampaio ${ }^{2}$, Thiago Haguihara ${ }^{2}$, Fernando Oak Ventin ${ }^{2}$ and Carlos Brites ${ }^{2}$ \\ ${ }^{1}$ Secretariat of Health of the State of Bahia; ${ }^{2}$ Federal University of Bahia; Salvador, BA, Brazil
}

\begin{abstract}
In Brazil, current trends of the AIDS epidemic include an increase in transmission through heterosexual contact, predominantly from men to women, with more cases of AIDS in women and more children contaminated by vertical transmission. There is also a high proportion of cases in poor people or people living in small towns. HIV-infected patients with high levels of immunodeficiency are frequently hospitalized after their first visit to the clinic due to opportunistic infections, characteristic of advanced disease. This study characterized the clinical and laboratory pattern of AIDS in a sample of patients attended for the first time in the AIDS clinic of the Federal University of Bahia Hospital (HUPES) in Salvador, Brazil. We revised medical charts of cases of subjects registered at the outpatient AIDS clinic from January 1997 to December 2003. The demographics, clinical data, and laboratory characteristics were analyzed to determine the degree of immunodeficiency at the time of admission. A total of 377 patients were evaluated (58.6\% were male, with a mean sample age of 33.4 years). The most frequent clinical manifestations were asthenia, weight loss, fever, anemia, dermatitis, oral thrush and diarrhea. CDC criteria were not adequate to define the initial cases. After admission to the outpatient clinic, nearly $25 \%$ of the patients were hospitalized immediately, indicating delay in the diagnosis. In Bahia, the initial presentation of HIV-infected patients to health care assistance is occurring at a late stage of the disease, when signs and symptoms of immunodeficiency are already established. Efforts are necessary to construct strategies to make an early diagnosis of these patients, improve the quality of care, and guarantee the benefits of antiretroviral therapy, when it is indicated.
\end{abstract}

Key-Words: AIDS, HIV infection, stage of disease, Brazil.

The first AIDS cases were reported 26 years ago [1]. Currently, the HIV epidemic has spread all over the world, causing a devastating public-health problem, especially in developing countries [2-4]. The UNAIDS estimates that at the end of 2006, 40 million people had HIV/AIDS in the world and it caused nearly 25 million of deaths occurred during the year [5].

In Brazil, the first cases of AIDS were identified in São Paulo and Rio de Janeiro, in 1982 [6]. From the southeastern region, the epidemic spread to northeast, center-west and north regions. By the end of February 2000, 59\% of the 5,507 Brazilian cities already had registered at least one case of AIDS, characterizing the dissemination of HIV epidemic [7]. To date, 433,067 AIDS cases had been notified to the Brazilian Ministry of Health, of which $67.2 \%$ were males. The demographic distribution has changed. The growth of the number of cases of HIV/AIDS through heterosexual transmission occurred simultaneously with an increase in its frequency. The male to female ratio fall from 15.1:1 in 1986 , to 1.5:1 in 2005. As a consequence, there was a gradual growth on HIV vertical transmission (from the infected mother to the baby) [8].

The state of Bahia ranks in seventh position in number of cases notified in Brazil (a total of 11,799 AIDS cases had been reported by the end of 2006) and it was first in the

Received on 22 January 2007; revised 12 July 2007.

Address for correspondence: Dr. Márcia Sampaio Sá. Rua João das Botas, s/n. Hospital Universitario Professor Edgard Santos, Unidade Docente Assistencial de Infectologia, $6^{0}$ andar. Canela, Salvador, Bahia, Brazil. Zip code: 40.110-160. Phone: 5571 3245-1903. Fax: $55713247-$ 2756. E-mail: sampaiomarcia@uol.com.br.

The Brazilian Journal of Infectious Diseases

2007;11(4):395-398. (C) 2007 by The Brazilian Journal of Infectious Diseases and Contexto Publishing. All rights reserved. northeast region. By December 2006, there were 4,388 patients under treatment with antiretroviral drugs in Bahia. In Salvador, the HIV/AIDS clinic of HUPES attends 1,042 patients using antiretroviral therapy, including 60 children.

AIDS is characterized by a wide spectrum of diseases, which includes opportunistic infections, malignancies, and other consequences of immune dysfunction [9-12]. Delay in the diagnosis of HIV infection can contribute to a higher rate of morbidity and mortality. The lack of studies on the profile of the AIDS patients in Bahia makes it difficult to implement effective strategies and programs to prevent its consequences and decrease the costs of management of such patients, for government and individuals.

\section{Materials and Methods}

We reviewed medical charts of patients attended at the HIV/AIDS clinic of HUPES in Salvador, Bahia, from 1997 up to 2003. We recorded demographic data, clinical and laboratory information, including initial staging of disease, diagnosis of opportunistic infections, CD4/CD8 cell counts and viral load at admission to the clinic. In addition, information on risk factors for HIV transmission was also collected. We also recorded information on the reasons for seeking medical advice, prior to diagnosis. A cut-off of 350 cells $/ \mathrm{mm}^{3}$ was used to define AIDS, based on Brazilian guidelines [13].

All collected data were stored in a database using EPIINFO software version 6.0, which was used for statistical analysis. Descriptive statistics included frequencies, means and standard-deviation and absolute and relative prevalence. Associations between categorical variables were evaluated using a $\chi^{2}$ test or the Fisher exact test. In addition, the student's $\mathrm{T}$ test was used to analyze quantitative variables. The tests were two-tailed and the level of significance was $5 \%$. 


\section{Results}

Table 1 gives the social-demographics characteristics of 377 patients who were evaluated. Nearly $59 \%$ were male. Mean age was 33.4 for women and 34.7 for men (ranged from 16 to 62 years of age). Regarding marital status, $59 \%$ were single and $54.2 \%$ of the sample had at least eight years of education, but this information was available from only 140 records.

The most important exposure category was heterosexual contact (65.8\%), followed by homosexual or bisexual contact (32.4\%). Twenty-five individuals (6.6\%) reported intravenous drug use. Only two patients had a documented history of blood transfusion. None were contaminated by vertical transmission or occupational exposure.

Ninety percent lived in Salvador, and the others came from several different cities in the state, without predominance of specific places. The main reasons for being HIV tested were clinical suspicion (56\%), followed by having an HIV- positive partner $(28.5 \%)$, occupational exposure $(7.5 \%)$, and spontaneous demand $(6.9 \%)$. When we analyzed the cases that reported an occurrence of percutaneous exposure, we concluded that the HIV test collected soon after the accident was already positive, removing the possibility of transmission by that route.

Table 2 describes the clinical manifestations at the moment of diagnosis. Asthenia, cachexia, fever, anemia, dermatitis, oral thrush and diarrhea were the most frequent clinical conditions. Kaposi's sarcoma and oral hairy leucoplakia were rare presentations, with less than $0.5 \%$ frequency.

Using CDC criteria, pneumocistosis and neurotoxoplasmosis were the most frequently diagnosed conditions, but they only occurred in $4.5 \%$ of AIDS patients in our sample. There were no cases of histoplasmosis and CNS primary lymphoma. After admission in the outpatient clinic, nearly $25 \%$ of the patients were hospitalized, demonstrating the delayed diagnosis (Table 3 ).

CD4 counts and viral load determination were available for 367 records, as seen in Table 4. CD4 counts ranged from 1 to 1,402 cells $/ \mathrm{mm}^{3}$ (mean of 289 cells, median of 229 cells). Forty-five per cent had CD4 counts less than 200 cells $/ \mathrm{mm}^{3}$, demonstrating advanced immunodeficiency. When we compared CD 4 values by sex, the CD 4 count was significantly lower in men $\left(266 \pm 228\right.$, median of 209 cells per $\left.\mathrm{mm}^{3}\right)$ than in women $\left(321 \pm 274\right.$, median of 265 cells per $\left.\mathrm{mm}^{3}, \mathrm{p}=0.01\right)$. Mean viral load was 264,000 copies (median of 61,000 copies). Men had a mean of 316,978 $\pm 857,871$ copies (median of 84,000 copies) and women had 196,499 $\pm 406,578$ copies (median of $38,000$ copies, $\mathrm{p}<0.001)$.

As expected, patients with CD4 counts ranging from 0 to $200 \mathrm{had}$ a greater frequency of fever, oral thrush, diarrhea, tuberculosis, and other clinical manifestations, when they were compared to patients with higher CD4 counts (Table 5).

Some degree of anemia (hemoglobin under $12.0 \mathrm{~g} / \mathrm{dL}$ ) was detected in $47 \%$ of the patients. Leucopenia (less than 4,000 cells $/ \mathrm{mm}^{3}$ ) was detected in $23 \%$ of cases. A negative tuberculin test was found in almost $76 \%$ of the cases. Serology for other
Table 1. Demographic characteristics of AIDS patients, in Bahia, Brazil

\begin{tabular}{lcr}
\hline & N & $(\boldsymbol{\%})$ \\
\hline Sex & & \\
$\quad$ Male & 221 & 58.6 \\
$\quad$ Female & 156 & 41.4 \\
Marital status & 222 & 58.8 \\
$\quad$ Single & 103 & 27.4 \\
$\quad$ Married & 16 & 4.2 \\
$\quad$ Widowed & 13 & 3.5 \\
$\quad$ Divorced & 23 & 6.1 \\
$\quad$ Not informed & & \\
Years of education & 3 & 2.1 \\
$\quad$ None & 61 & 43.6 \\
$\quad$ to 7 (Primary/Secondary) & 76 & 54.2 \\
$\quad$ 8 or more (High school or college) & & \\
Exposure category & 72 & 19.1 \\
$\quad$ Homosexual & 248 & 65.8 \\
$\quad$ Heterosexual & 50 & 13.3 \\
Bisexual & 25 & 6.6 \\
Intravenous drug use & 2 & 0.5 \\
$\quad$ Blood transfusion & & \\
\hline
\end{tabular}

Table 2. Clinical presentation of the patients, using Caracas criteria, at the moment of admission to the AIDS clinic, in Bahia, Brazil

\begin{tabular}{lcr}
\hline Clinical presentation & N & $\mathbf{( \% )}$ \\
\hline Kaposi's Sarcoma & 3 & 0.3 \\
Disseminated tuberculosis & 30 & 2.9 \\
Oral thrush & 90 & 8.5 \\
Oral hairy leucoplakia & 3 & 0.3 \\
Pulmonary tuberculosis & 59 & 5.6 \\
Herpes zoster & 23 & 2.2 \\
CNS dysfunction & 16 & 1.5 \\
Diarrhea & 65 & 6.1 \\
Fever & 121 & 11.4 \\
Cachexia & 166 & 15.6 \\
Asthenia & 177 & 16.7 \\
Persistent dermatitis & 93 & 8.8 \\
Anemia & 118 & 11.2 \\
Persistent cough & 50 & 4.7 \\
Lymphopenia & 44 & 4.2 \\
Total & 1058 & 100 \\
\hline
\end{tabular}

Table 3. Clinical presentation of the patients, using CDC criteria, at the moment of admission to the outpatient AIDS clinic, in Bahia, Brazil

\begin{tabular}{lcr}
\hline Disease & N & $\mathbf{( \% )}$ \\
\hline Pneumocystis jiroveci pneumonia & 9 & 37.5 \\
Ocular CMV & 5 & 20.8 \\
Neurotoxoplasmosis & 8 & 33.3 \\
Cryptococcosis & 1 & 4.2 \\
Cryptosporidyosis & 1 & 4.2 \\
Total & 24 & 100 \\
\hline
\end{tabular}


Table 4. Distribution of CD4 counts and viral load, in the HIV patient sample in Bahia, Brazil

\begin{tabular}{lcccc}
\hline CD4 $\left(\mathbf{m m}^{3}\right)$ & $\mathbf{0 - 1 0 , 0 0 0}$ & $\mathbf{1 0 , 0 0 1 - 1 0 0 , 0 0 0}$ & $\mathbf{> 1 0 0 , 0 0 1}$ & Total \\
\hline $0-199$ & 28 & 32 & 104 & $164(44.7)$ \\
$200-399$ & 25 & 51 & 23 & $99(27.0)$ \\
$400-599$ & 24 & 29 & 11 & $64(17.4 \%)$ \\
$600-999$ & 23 & 10 & 2 & $35(9.5 \%)$ \\
$>1000$ & 4 & 1 & 0 & $5(1.4 \%)$ \\
Total & 104 & 123 & 140 & 367 \\
& $(28.3 \%)$ & $(33.5 \%)$ & $(38.2 \%)$ & $(100 \%)$ \\
\hline
\end{tabular}

Table 5. Clinical manifestations according to CD4 counts, at the moment of AIDS diagnosis in Bahia, Brazil

\begin{tabular}{lccccc}
\hline CD4 (/mm3) & $\mathbf{0 - 1 9 9}$ & $\mathbf{2 0 0 - 3 9 9}$ & $\mathbf{4 0 0 - 5 9 9}$ & $\mathbf{7 6 0 0}$ & Total $(\mathbf{N})$ \\
\hline Kaposi's sarcoma & 2 & 1 & 0 & 0 & 3 \\
Disseminated tuberculosis & 23 & 3 & 3 & 1 & 30 \\
Candidiasis & 67 & 12 & 6 & 5 & 90 \\
Leucoplakia & 2 & 1 & 0 & 1 & 3 \\
Pulmonary tuberculosis & 44 & 10 & 1 & 4 & 59 \\
Herpes & 10 & 12 & 0 & 1 & 23 \\
CNS dysfunction & 16 & 0 & 0 & 0 & 16 \\
Diarrhea & 47 & 7 & 6 & 5 & 65 \\
Fever & 89 & 16 & 10 & 6 & 121 \\
Pneumocystis jiroveci pneumonia & 8 & 0 & 1 & 0 & 9 \\
\hline
\end{tabular}

Table 6. Frequency of positive serology for other infectious agents, at the moment of admission to the AIDS clinic in Bahia, Brazil

\begin{tabular}{lccr}
\hline Test & $\mathbf{n}$ & $\mathbf{N}$ & $\mathbf{( \% )}$ \\
\hline AgHBS & 6 & 247 & 2.4 \\
HCV & 18 & 232 & 7.7 \\
Toxoplasmosis IgG & 199 & 249 & 79.9 \\
CMV IgG & 226 & 245 & 92.2 \\
EBV IgG & 63 & 79 & 79.7 \\
HSV IgG & 143 & 157 & 91.1 \\
VDRL & 38 & 283 & 13.4 \\
HTLV & 9 & 105 & 8.6 \\
\hline
\end{tabular}

infectious agents were requested for all patients at admission, but the results of these tests were not registered in great part (ranging from $25 \%$ to $79 \%$ ) of the charts. These findings are showed in Table 6. Positive tests were found for CMV, HSV, EBV and toxoplasmosis for the vast majority of the patients, reflecting previous infection or polyclonal activation. Coinfection with syphilis (13.4\%), HTLV (8.6\%), hepatitis C $(7.7 \%)$ and hepatitis B $(2.4 \%)$ were often diagnosed in these patients.

\section{Discussion}

The demographics for this sample were similar to that of AIDS patients in the state of Bahia, with a greater predominance of single men, ranged from 20 to 49 years old. The education level was higher than that for the reference population. However, this type of data was available from less than half of the charts. When we analyzed the exposure category for both men and women, there was predominance of sexual transmission, mainly through heterosexual contact. Blood transfusion as a source for HIV transmission has been rarely registered in last years, reflecting the improvement in blood quality. The absence of cases through occupational exposure confirms the official data. It was demonstrated that individuals who indicated occupational exposure had an additional source of HIV infection. As the data was collected only from adult clinics, the absence of AIDS cases by vertical transmission is justified.

The analysis of reasons for being HIV tested suggests delayed diagnosis, since clinical suspicion and having an HIVpositive partner were the main reasons. Spontaneous demand that could denote risk perception for HIV transmission was mentioned by only seven percent of the sample.

The occurrence of asthenia, cachexia, fever, anemia, diarrhea, dermatitis and oral thrush, as the clinical presentation at the time of diagnosis, suggests that patients are seeking medical assistance only in the phase of clinical illness. Analysis using CDC criteria was less sensitive than that with Caracas criteria. Clinical findings were similar to those of Moreira, who analyzed a cohort of 111 patients with AIDS in Bahia [14]. In that study, the main clinical manifestations were also oral thrush, tuberculosis, $P$. carinni pneumonia and neurotoxoplasmosis. The high rate of hospitalization immediately after admission in the outpatient clinic strongly suggests delay in AIDS diagnosis in our state. 
The findings of low values for CD4 counts at admission to the hospital demonstrate that a high level of immunodeficiency was already presented, defining advanced AIDS. Almost 70\% of the patients had CD4 values less than 400 cells $/ \mathrm{mm}^{3}$. These values are near to the cut-off of 350 cells $/ \mathrm{mm}^{3}$ used by Brazilian guidelines to define AIDS through laboratory criteria. There were also patients with CD4 counts above 400 cells $/ \mathrm{mm}^{3}$ presenting signs and symptoms at the moment of the initial evaluation. It is possible that HTLV-1 co-infection can play a role in this group, since co-infection can raise the CD4 counts, without immunological benefits for the patient [15]. Unfortunately a definitive correlation cannot be established, since not all patients had been tested for this agent.

The finding of higher values of CD4 counts among women could indicate a better level of "self-care", and a tendency to seek health care services earlier than men. Viral-load values were high in the vast majority of the patients, reaching levels of more than one million copies in about $8 \%$ of the cases. Again, higher values of viral load among men are suggestive of a delayed arrival at health care services.

Anemia and lymphopenia, characteristics of advanced illness, were detected in $11 \%$ and $4 \%$ of patients, respectively, strengthening the hypothesis of delayed diagnosis. The negative tuberculin test in $76.4 \%$ of the cases is also indicative of the immunodeficiency level. The serological profile evidenced co-infection with syphilis, HTLV, hepatitis C and hepatitis B, probably due to sharing of transmission sources for those infectious agents.

In conclusion, clinical and laboratory findings from our patients suggest that there is a delay in the diagnosis of AIDS in the state of Bahia, Brazil, despite media campaigns targeting the general population to prevent HIV acquisition and specific medical training of health professionals. Strategies to improve identification of cases of AIDS are necessary, through increasing access to diagnostic facilities and through qualification of health professionals, in order to increase the degree of clinical suspicion of this illness.

\section{References}

1. CDC. Center for Disease Control. Pneumocystis pneumonia Los Angeles. Morbidity and Mortality Weekly Report, 1981;30:250-2.

2. Steinbrook R., Drazen J.M. AIDS - Will the next 20 Years be different? New England Journal of Medicine 2001;344(23):1781-2.

3. Gotlieb M.S. AIDS - Past and Future. New England Journal of Medicine 2001;344(23):1788-91.

4. Sepkowitz K. AIDS - The First 20 Years, New England Journal of Medicine 2001;344(23):1764-72.

5. UNAIDS/WHO, Joint United Nations Programme on HIV/AIDS/ World Health Organization, AIDS epidemic update: December 2006, Geneva, 2006.

6. CN-DST-AIDS / MS, Coordenação Nacional de DST/AIDS / Ministério da Saúde. Brasília. A epidemia da AIDS no Brasil. In: AIDS no Brasil: Um Esforço Conjunto Governo - Sociedade, Brasília, p. 11-8, 1998.

7. CN-DST-AIDS / MS, Coordenação Nacional de DST/AIDS / Ministério da Saúde. Brasília. Situação da Epidemia no Brasil. In: Programa Brasileiro de DST/AIDS, Brasília, p. 6-9, 2000.

8. Ministério da Saúde, Brasília. Boletim Epidemiológico AIDST 2006; Ano III (1) - janeiro-junho.

9. Lipson A.R., Rutherford G.W., Jaffe, H.W. The natural history of human immunodeficiency virus infection. Journal of Infectious Diseases 1988; $158: 1360-7$.

10. Fox R., Eldred L.J., Fuchs E.J., et al. Clinical manifestations of acute infection with the human immunodeficiency virus in a cohort of gay men. AIDS 1987;1:35-8.

11. Learmont J., Tindall B., Evans L., et al. Long-term symptomless HIV-1 infection in recipient of blood products from a single donor. Lancet 1992;340:863-7.

12. Keet I.P., Krol A., Klein M.R., et al. Characteristics of long-term assymtomatic infection with human immunodeficiency virus type 1 in men with normal and low CD4+ cell counts. Journal of Infectious Diseases 1994;169:1236-43.

13. Ministério da Saúde. "Definição Nacional de Caso de AIDS em Indivíduos com 13 anos de idade ou mais, adotada pelo Ministério da Saúde para fins de Vigilância Epidemiológica”, 2004.

14. Moreira Jr. E.D., Silva N., Brites C., et al. Characteristics of the Acquired Immunodeficiency Syndrome in Brazil. American Journal of Tropical Medicine and Hygiene 1993;48(5):687-92.

15. M. Schechter, L.H. Harrison, N.A. Halsey, et al. Coinfection with human T-cell lymphotropic virus type I and HIV in Brazil. Impact on markers of HIV disease progression JAMA 1994;271:353-7. 